\title{
POLLUTANT CONTENT IN MARINE DEBRIS AND CHARACTERIZATION BY THERMAL DECOMPOSITION
}

\author{
Iñiguez*, M.E.; Conesa, J.A.; Fullana, A. \\ Chemical Engineering Department. University of Alicante. P.O. Box 99, 03080 Alicante (Spain). \\ Phone: +(34) 965903867 Fax: +(34) 965903826 \\ * Corresponding author email: maria.iniguez@ua.es
}

\begin{abstract}
Marine debris (MDs) produces a wide variety of negative environmental, economic, safety, health and cultural impacts. Most marine litter has a very low decomposition rate (plastics), leading to a gradual accumulation in the coastal and marine environment. Characterization of the MDs has been done in terms of their pollutant content: PAHs, CIBzs, CIPhs, BrPhs, PCDD/Fs and PCBs. The results show that MDs is not a very contaminated waste. Also, thermal decomposition of MDs materials has been studied in a thermobalance at different atmospheres and heating rates. Below $400-500 \mathrm{~K}$, the atmosphere does not affect the thermal degradation of the mentioned waste. However, at temperatures between 500 and $800 \mathrm{~K}$ the presence of oxygen accelerates the decomposition. Also, a kinetic model is proposed for the combustion of the MDs, and the decomposition is compared with that of their main constituents, i.e., polyethylene (PE), polystyrene (PS), polypropylene (PP), nylon and polyethylen-tereftalate (PET).
\end{abstract}

Keywords: Marine debris; Pollutants; Kinetic; Combustion; Decomposition

\section{Introduction}

"Marine litter is defined as any persistent, manufactured or processed solid material discarded, disposed or abandoned in the marine and coastal environment"(Coe and Rogers, 
1997; Galgani et al., 2010). It consists of items that have been made or used by people and deliberately discarded into the sea or rivers or on beaches; brought indirectly to the sea with rivers, sewage, storm water or winds; accidentally lost, including material lost at sea in bad weather (fishing gear, cargo); or deliberately left by people on beaches and shores (UNEP, 2009).

The presence of marine debris is a cause for concern due to several reasons. It is known to be harmful to organisms and to human health (Coe and Rogers, 1997; Derraik, 2002; Gregory, 2009; Rochman et al., 2013b), it has potential to increase the transport of organic and inorganic contaminants (Gaylor et al., 2012; Holmes et al., 2012; Mato et al., 2001; Rochman et al., 2013a; Teuten et al., 2009), it presents a hazard to shipping, and it is aesthetically detrimental, and thus generating negative socio-economic consequences (Mouat et al., 2010).

The material most commonly found in marine debris are glass, metal, paper and plastic (OSPAR, 2007), and, according to the published literature, it is clearly apparent that, globally, plastic items are consistently the most abundant type of marine debris (OSPAR, 2007; Thompson et al., 2009; UNEP-CAR/RCU, 2008; UNEP, 2005, 2009). The most commonly used plastics are polyethylene (PE), polypropylene (PP) and polyethylene terephthalate (PET), therefore, they are the most frequently found in the marine environment too (Heo et al., 2013; Hidalgo-Ruz et al., 2012; Iñiguez et al., 2016; Martins and Sobral, 2011).

Recent surveys estimate that between 4.8 and 12.7 million tons of plastic waste ends up in the world's oceans every year (Jambeck et al., 2015). The annual input of plastics in the oceans increases every year. It is estimated that in 2015 around 9.1 million tons were accumulated. By 2025, the annual input of plastics to the sea would be about double what it was in 2010. By then, the total amount of plastic debris accumulated in the oceans around the world is estimated around 155 million tons (Jambeck et al., 2015).

Pyrolysis and combustion have always been considered as attractive alternatives for waste disposal, since these techniques provide a reduction in volume of waste and also involve profitable energetic and/or chemical products. Thermal decomposition of waste can take place both in controlled conditions (incinerators, cement kilns...) and non-controlled conditions, for 
example, during fires or open-air burning. The substances emitted during non-controlled plastic thermal degradation may create a serious hazard for human health and for the environment (Iñiguez et al., 2016).

Until now plastic fractions of marine debris have been landfilled because it was considered as a waste product with low value; however, today it is known that this waste has a great value and it is suitable for recycling, mainly by chemical or energy recovery, especially attractive for polyolefin waste (Hagstrom et al., 2006).

Some marine debris cannot be recycled or reused. On most countries, incineration is the most widely used process to treat marine debris (Jung et al., 2010). In this process, the production of air pollutants requires special attention, since incomplete combustion of these can generate harmful gases. Furthermore, due to chlorine, generation of dioxins in this process is important and must be measured.

In the present work, characterization of the pollutant content of the MDs is done, and a kinetic model for their thermal decomposition is proposed, considering the decomposition in different atmospheres and heating rates.

\section{Materials}

Over several months, it has been carried out the MDs collection in areas near the ports of Torrevieja and Santa Pola (Mediterranean coast). The MDs sample used in this study was selected from the residues collected during one day, and has been considered representative of a conventional marine waste. The selection was made taking into account the major components, especially plastic ones, as well as the proportions in which each of the different collected residues are found in the sea.

Besides of the MDs, the five main plastics components in marine litter were studied for thermal decomposition (Iñiguez et al., 2016). In this way, PE, PP, PET, Nylon and PS were subjected to decomposition in the thermobalance. 


\section{Methods and Equipment}

\subsection{Characterization of MDs}

An elemental analysis was performed to a representative sample (carbon, hydrogen, nitrogen and sulfur) performed by oxidation of the sample to $1000{ }^{\circ} \mathrm{C}$ and subsequent detection of combustion products $\left(\mathrm{CO}_{2}, \mathrm{H}_{2} \mathrm{O}, \mathrm{N}_{2}\right.$ and $\left.\mathrm{SO}_{2}\right)$ that are separated into specific columns to be thermally desorbed thereafter. The gases pass separately by a thermal conductivity detector which provides a signal proportional to the concentration of each of the individual components of the mixture. The initial weight of the sample was $50 \mathrm{mg}$, and sulfamethazine was employed as internal standard. The equipment used was a Perkin-Elmer 2400 (Perkin-Elmer, UK); the amount of sulfur detected in this equipment was nil, and so an additional analysis was performed in a Total Carbon and Nitrogen Analyzer "TruSpec CN" LECO, with Sulphur module that used Vanadium Pentoxide. This analysis indicated that the amount of Sulphur is 0.098 wt. $\%$. Also, the humidity of the samples after 2 months at room temperature and the ash content were measured (UNE-EN ISO 2016). The Net Calorific Value (NCV) was determined using a calorimetric bomb AC-350 Leco Instruments, and the halogen content of the sample was measured by ionic chromatography following EPA method 5050 (US EPA, 2007b).

A detailed analysis of various pollutants contained in the MDs was done in order to characterize the sample and get knowledge of its possible origin. Two different samples were taken and analyzed for the content of polychlorinated biphenyls (PCBs), toxic dioxins and furans (PCDD/Fs), polycyclic aromatic hydrocarbons (PAHs), chlorinated benzenes (ClBzs) and brominated and chlorinated phenols (BrPhs and CIPhs).

In order to determine PAHs, CIBzs, CIPhs and BrPhs in the samples, four different internal standards were added to them before extraction: $5 \mu \mathrm{L}$ of deuterated PAH Mix 26 (Dr. Ehrenstorfer-Schäfers, Augsburg, Germany), $10 \mu \mathrm{L}$ of 13C-labelled CIPh, $10 \mu \mathrm{L} 13 \mathrm{C}$-labelled $\mathrm{CIBz}$ and $100 \mu \mathrm{L}$ 13C-labelled $\mathrm{BrPh}$ (Wellington Laboratories, Ontario, Canada). Later, extraction was done in a mixture of dichloromethane-acetone (1:1) by Accelerated Solvent Extraction (ASE-100 Dionex-Thermo Fisher Scientific, California, USA) following the U.S. EPA method 3545A (US EPA, 2007a). The extract was concentrated in a rotary evaporator and with 
a moderate stream of nitrogen up to $1.5 \mathrm{~mL}$. Finally, $6 \mu \mathrm{g}$ of anthracene-d10 (AccuStandard, New Haven, USA) was spiked as a recovery standard.

The quantification of the 16 priority PAHs established by U.S. EPA (1998) was done following the U.S. EPA method 8270D (US EPA, 2007b, c) in a GC-MS (Agilent GC $6890 \mathrm{~N} /$ Agilent MS 5973N, Agilent Technologies, USA), in the SCAN mode with a HP-5 MS capillary column (Agilent Technologies, USA). CIPhs, CIBzs and BrPhs were analysed in the same equipment but employing the SIR mode.

In order to analyze PCDD/Fs and dioxin-like PCBs, U.S. EPA method 1613 (US EPA, 1994b) and U.S. EPA method 1668 C (US EPA, 2010) were used, respectively. ${ }^{13} \mathrm{C}$-labeled analogues were added to the samples as internal standards (10 $\mu \mathrm{L}$ of LCS-1613 for PCDD/Fs and $10 \mu \mathrm{L}$ WP-LCS for PCBs (Wellington Laboratories, Ontario, Canada)) and an accelerated extraction with toluene was performed in an ASE 100 Dionex apparatus.

These extracts were purified and fractionated in an automated Power Prep® system (FMS, Inc., Boston, MA), obtaining two fractions (PCDD/Fs and PCBs). Both fractions were concentrated in nonane with a stream of nitrogen and, finally, recovery standards were added (10 $\mu \mathrm{L}$ of ISS-1613 for PCDD/Fs and $10 \mu \mathrm{L}$ WP-ISS for PCBs (Wellington Laboratories, Ontario, Canada)). The analytical determination of these compounds used an Agilent HP5890 High Resolution Gas Chromatographer coupled to a Micromass Autospec Ultima NT High Resolution Mass Spectrometer (HRGC-HRMS).

\subsection{Decomposition curves of MDs in different atmospheres}

In order to get a better knowledge of the MDs decomposition behavior, thermogravimetric runs were performed in different atmospheres.

Runs for the TG analysis were carried out on a Mettler Toledo TGA/SDTA851e/SF/1100 Thermal Gravimetric Analyzer. The decomposition temperatures were measured under dynamic conditions in different atmospheres such as nitrogen and mixtures of nitrogen and oxygen (4:1 and 9:1) with a total flow rate of $100 \mathrm{~mL} \mathrm{~min}^{-1}$. The experiments were carried out at heating 
rates of 5,10 and $20 \mathrm{~K} \mathrm{~min}^{-1}$ for each atmosphere, from room temperature up to $1173 \mathrm{~K}$. For each run, $6 \pm 0.3 \mathrm{mg}$ of sample were used.

\subsection{Kinetic model optimization method (combustion)}

Thermal decomposition of each of the five main plastics components and also of the MDs were studied under $\mathrm{N} 2: \mathrm{O} 2=4: 1$ atmosphere (approx. synthetic air) in order to compare their decomposition curves.

The kinetic model proposed for thermal decomposition of each plastic component considers each material formed by one or two independent parts (depending on the plastic), each one following an independent reaction, as follows:

$$
\mathrm{c}_{\mathrm{Si} 0} \text { Solid }_{\mathrm{i}} \stackrel{i-\text { th reaction }}{\longrightarrow}\left(\mathrm{c}_{\mathrm{Si} 0}-\mathrm{v}_{\mathrm{i} \infty}\right) \text { Residue }_{i}+\mathrm{v}_{\mathrm{i} \infty \text { Oolatiles }_{i}}
$$

with $\mathrm{i}=1$ or 2 . In the previous equation, Solid refers to different fractions of the original material, Volatiles $_{\mathrm{i}}$ are the gases and condensable volatiles evolved in the corresponding reactions and Residue $_{\mathrm{i}}$ is the possible residue formed in the decomposition of each Solid ${ }_{\mathrm{i}}$. Each fraction has a yield coefficient (considered constant throughout the reaction) representing the maximum mass fraction obtainable by each reaction. In this way, $v_{i \infty}$ is the yield coefficient for the Volatiles ${ }_{i}$ and $\left(\mathrm{C}_{\mathrm{Si0}}{ }^{-} \mathrm{v}_{\mathrm{i}}\right)$ is the yield coefficient for the Residue ${ }_{\mathrm{i}}$. On the other hand, the sum of initial mass fractions of the components $\left(\mathrm{c}_{\mathrm{Sio}}\right)$ is exactly one minus the final mass fractions of solid (Grønli et al., 2002).

The conversion degree for each reaction is defined as the ratio between the mass fractions of solid reacted at any time $\left(\mathrm{c}_{\mathrm{Si}}-\mathrm{W}_{\mathrm{Si}}\right)$ and the corresponding initial fraction of this component: $\alpha_{i}=\frac{c_{S 0 i}-w_{S i}}{c_{S i 0}}, \quad i=1,2$

From the mass balance between products and reactants and the conversion degrees, the kinetic equations for decomposition runs can be defined as follows:

$$
-\frac{d\left(\frac{w_{S i}}{c_{S i 0}}\right)}{d t}=k_{i}\left(\frac{w_{S i}}{c_{S i 0}}\right)^{n_{i}} \quad \text { or } \quad \frac{d \alpha_{i}}{d t}=k_{i}\left(1-\alpha_{i}\right)^{n_{i}}
$$


with $n_{i}$ being the reaction order and the kinetic constants following the Arrhenius equation. For the sake of simplicity, and bearing in mind that a great variety of materials follow first order decompositions (Caballero and Conesa, 2011; Várhegyi, 2007), all values of reaction orders have been maintained to unity, i.e., $\mathrm{n}_{\mathrm{i}}=1$ in all cases.

For calculation of the total mass remaining a weighted sum is used:

$$
-\frac{d w_{s}^{c a l}}{d t}=\sum_{i} c_{S i 0} \frac{d \alpha_{i}}{d t} \quad \text { and } \quad w_{s}^{c a l}=1-\sum_{i} c_{S i 0} \alpha_{i}
$$

The optimization was done by integration of the differential equations presented in the kinetic model by the Euler method considering and testing that the intervals of time were small enough to make the integration errors negligible. The optimization method of the function Solver in a Microsoft Excel spreadsheet was used to minimize the differences between the experimental and calculated mass fraction and their derivatives. The objective function (OF) to be minimized was:

$$
O F=\sum_{m=1}^{M} \sum_{p=1}^{P}\left(w_{S, p}^{c a l}{ }_{m, p}^{\text {exp }}{ }_{m, p}\right)^{2}+\text { factor } \sum_{m=1}^{M} \sum_{p=1}^{P}\left(\frac{d w_{S}^{\text {cal }}{ }_{m, p}}{d t}-\frac{d w_{S}^{\text {exp }} m, p}{d t}\right)^{2}
$$

Where ' $p$ ' represents the experimental data at time ' $t$ ' in the experiment with a heating rate ' $m$ '. The value of $M$ is the number of runs and $P$ is the number of points in each run. The value of the 'factor' was arbitrarily chosen to be $10^{+3}$, in order to give similar contribution to the O.F. to the mass fraction differences and those of the derivatives. Note that with this methodology, a unique set of kinetic constants is calculated from the experimental curves obtained at different heating rates, and it gives kinetic constants valid for the whole set of heating rates used.

The points used for the kinetic analysis, have been selected according to techniques recommended by Caballero and Conesa (2005) so that the derivative of the points is calculated accurately and correctly, the points are equally spaced on a representation derivative of weight versus temperature and the fitting is simultaneous, with no variation of the kinetic constants, for at least three different heating rates. 
With the objective of decreasing the great interrelation existing among the pre-exponential factor, the activation energy and the reaction order, the optimization was carried out using a “comparable kinetic constant" $k_{i}^{*}$ instead of optimization of $k_{i 0}$ (Martín-Gullón et al., 2003).

$$
k_{i}^{*}=k_{i 0} \exp \left(\frac{-E_{i}}{R T_{\max }}\right)(0.64)^{n_{i}}
$$

In the previous equation, $T_{\max }$ is the temperature where maximum rate of decomposition is experimentally observed, and $n_{i}=1$ in the present calculation for all polymers.

In order to explain experimental curves, thermal decomposition in synthetic air of the MDs has been considered as a weighted sum of the decomposition of each of the five main constituents, in such a way that:

$$
-\frac{d w_{M D}{ }^{c a l}}{d t}=\sum_{j} f_{j 0} \frac{d \alpha_{j}}{d t} \quad \text { and } \quad w_{M D}{ }^{c a l}=1-\sum_{j} f_{j 0} \alpha_{j}
$$

In the previous equation, $\mathrm{w}_{\mathrm{MD}}$ represents the calculated weigh fraction of the marine debris, and 'j' refers to each component (i.e. PET, PS, PE, PP and Nylon). In the equation $f_{j 0}$ represents the weight contribution of each of the components to the total weight.

\section{Results}

\subsection{Characterization of MDs and pollutant content}

The results for elemental analysis of a representative sample of MDs are presented in Table 1. In this Table is also shown the humidity of the samples after 2 months at room temperature, the ash content and the halogen content of the sample; it is remarkable the high chlorine content $(1,83 \%)$, value that is logical bearing in mind that the sample comes from a saline environment. The Net Calorific Value (NCV) was $25.6 \mathrm{MJ} / \mathrm{Kg}$.

Details of the analysis of PAHs, CIBzs, BrPhs and CIPhs are shown in Tables SI1, SI2 and SI3 of the Supporting Information. In general, reproducibility of analysis is difficult mainly due to the heterogeneity of the sample. The main PAH present in the sample is naphthalene with a content close to $100 \mathrm{ng} / \mathrm{g}$. Total chlorobenzenes is in the range $180-215 \mathrm{ng} / \mathrm{g}$, being $1,2-$ dichlorobenzene the most abundant isomer in two different samples. On the other hand, 
approximate chlorophenols content is $105 \mathrm{ng} / \mathrm{g}$ and bromophenols ranged $58-77 \mathrm{ng} / \mathrm{g}$. As comparative data, in our laboratory total amount of chlorophenols measured in furniture wood waste (Moreno et al., 2016) is nearly $100 \mathrm{ng} / \mathrm{g}$ whereas not chlorobenzenes were detected. Respect to the PAHs content, furniture wood waste presents a total amount of $645 \mathrm{ng} / \mathrm{g}$ whereas solid and pine wood does not present a detectable amount. This shows up that MDs is not a very contaminated waste, the only remarkable difference is the high amount of chlorobenzenes, which may be comparable to that found in vegetable soils (Song et al., 2012) or sediments of rivers (Cai et al., 2007).

The results for the analysis of PCDD/Fs in the two samples of MDs mentioned above are presented in Table 2. The total content of such pollutants is in the range 0,9-1,2 pg WHO-TEQ/g (0,95-1,17 pg I-TEQ/g), similar to other wastes analyzed in our laboratory (Conesa et al., 2008; Fuentes et al., 2007; Moltó et al., 2005; Moltó et al., 2006): cotton and polyester textiles presented a level of 3-10 pg I-TEQ/g, sewage sludge between 5 and $8 \mathrm{pg} / \mathrm{g}, \mathrm{PVC} 0,6 \mathrm{pg} / \mathrm{g}$ and meat and bone meals had the lower dioxins and furans content $(0,3 \mathrm{pg} / \mathrm{g})$. A reference in literature has been found doing a similar analysis in sediment collected from offshore waters of Central Vietnam (Tri et al.). The total content of such pollutants in these sediments $(1,8 \mathrm{pg}$ WHO-TEQ/g) is similar to that obtained in this study.

In order to investigate the congener profile in the MDs samples, a principal component analysis (PCA) has been done considering different profiles published in literature. On the one hand, a study performed in the USA considering different sources (Cleverly, 1997) has been used. This study comprises eighteen chlorinated patterns: MSWI (mass burn-water wall w/hotside ESP), MSWI (mass burn-water wall w/ds), Medical Waste Incinerators (w/o APCD), Hazardous Waste Incinerators, Cement Kilns Burning Haz Waste, Cement Kilns Not Burning Haz Waste, Industrial Oil-Fired Boilers, Industrial/Utility Coal Combustors, Industrial Wood Combustors, Unleaded Gasoline Vehicles (w/ cat. conv.), Diesel Trucks (tailpipe emissions), Diesel Trucks (Baltimore Tunnel), Secondary Aluminum Smelters, Secondary Lead Smelters, Sewage Sludge Incinerators, Paper Pulp, Technical Pentachlorophenol (PCP), and 2,4-D Salts and Esters. On the other hand, different profiles were taken from literature: cotton and polyester textiles (Moltó et al., 2005; Moltó et al., 2006), meat and bone meal (MBM) (Conesa et al., 
2005a), sewage sludges (Conesa et al., 2005b), paper wastes (Conesa et al., 2008), used oils (Fuentes et al., 2007), solid recovered fuel from municipal solid wastes (Conesa et al., 2011), air and soil from Tarragona province (300 km away from the sampling point) (Rovira et al., 2015), air filters taken in our work place (Conesa and Galvez, 2006), fish liver (Orrego et al., 2005) and two different fish oils (Ábalos et al., 2010).

For the PCA nonequivalent toxic units were used, and the amount of each congener is normalized to the total amount of PCDD+PCDF. Figure 1 presents scatter plot and correlation between all profiles used and first two principal components. Note that MDs congener profile is similar to that found in MBM wastes, and also in air and soil samples from nearby areas, with a predominance of the hepta- and hexa-chlorinated congeners.

Results for the analysis of PCBs in the two samples mentioned above are presented in Table 3. Total toxicity of PCBs is in the range $0,45-0,48 \mathrm{pg}$ WHO-TEQ/g, representing ca. $30 \%$ of the dioxin-like compounds toxicity. Literature reports a wide variability on the PCBs contribution to the total WHO-TEQ. For example, PCBs contribution in fish oils ranged from 65 to $80 \%$ (Ábalos et al., 2010), whereas the percentage is much lower (ca. $2 \%$ ) in other wastes as polyester textiles (Moltó et al., 2006).

\subsection{Decomposition curves in air atmosphere and kinetic model}

Experimental curves for decomposition at $20 \mathrm{k} / \mathrm{min}$ of PE, PS, PP and PET together with the calculated ones can be seen in Figure 2. For the calculated curves, and bearing in mind the form of each curve (Figure 2), two different fractions ( $i=2$ ) where considered in the case of PET, Nylon and PE, whereas a single fraction $(i=1)$ was necessary to explain PS and PP decomposition.

The optimized parameters for each plastic material are presented in Table 4. Figure 2 shows the calculated curves, which explain in a very convenient way the experimental results. In all the decomposition activation energies are in the range $120-230 \mathrm{KJ} \mathrm{mol}^{-1}$, what is the range suggested in literature (Vyazovkin, 2000; Vyazovkin et al., 2011a) 
On the other hand, Figure 3 presents the thermal decomposition of the MDs in air atmosphere, at three heating rates. As can be seen, the increase of heating rate shifts the curve to higher temperatures, as usual in other materials.

As mentioned before, the calculation of the MDs decomposition curves, and bearing in mind that each plastic component has already been modelled, is merely to calculate the best values of $f_{j 0}$ in equation 6 (note that only 4 values are needed to be calculated). Figure 3 shows the result of this procedure, with the following contributions to the total wight: $0 \%$ PS; $18,8 \%$ PET; $12,8 \%$ PP; $27,5 \%$ PE and 24,8 \% Nylon, i.e., for the simulation of the decomposition curve there Is no need of the PS decomposition as the calculated fraction of this polymer is zero. These are very reasonable contributions and explain very well the obtained curves at the three heating rates used in the present study (see Figure 3).

\subsection{Decomposition curves of MDs in different atmospheres}

Figure 4 shows the thermal decomposition runs at different heating rates in nitrogen and a mixture $\mathrm{N}_{2}: \mathrm{O}_{2}=9: 1$ (10\% Oxygen). As can be seen, bellow $480-500 \mathrm{~K}$ actual atmosphere does not influence thermal degradation because the mass loss is due to vaporization of light components. In other temperature range, the presence of oxygen accelerates the decomposition, as it occurs in other materials (Font et al., 2011; Moliner et al., 2016; Niu et al., 2016), and the mass loss is higher. The introduction of a richer oxygen atmosphere (Figure 3 , previous section) does not produce dramatic changes in the decomposition, and simply a slight acceleration respect to the $10 \%$ oxygen atmosphere is observed.

At these higher temperatures it does not occur volatilization but cracking, as the heavy molecules, which are more resistant to the thermo-degradation, are broken, yielding volatiles and char (carbonaceous residue) which accounts for the weight in the thermobalance. This residue is not decomposed in inert atmosphere but is fast oxidized in the presence of a reacting 
species as oxygen. For this reason, at temperatures over $700 \mathrm{~K}$ the mass loss rate is higher in combustion runs than in pyrolysis.

\section{Conclusions}

The present study shows up that MDs is not a very contaminated waste. The pollutant content is comparable to other wastes analyzed in our laboratory, or samples collected from rivers or vegetable soils studied by other authors. The sulfur content of the sample is very low and it is notable the high chlorine content, which can be explained by the presence of this waste in seawater.

This study is the first analysis of thermal decomposition performed on a sample of MDs. Our results revealed that below $400-500 \mathrm{~K}$, the atmosphere does not affect the thermal degradation. However, at temperatures between 500 and $800 \mathrm{~K}$ the presence of oxygen accelerates the decomposition, so the mass loss rate is higher in combustion than in pyrolysis.

\section{Acknowledgements}

Support for this work was provided Spanish Ministry of Culture and Sport and by the CTQ2016-76608-R project from the Ministry of Economy and Competitiveness (Spain) and the PROMETEOII/2014/007 project from the Valencian Community Government (Spain).

\section{Literature cited}

Ábalos, M., Parera, J., Rivera, J., Abad, E., 2010. PCDD/F and DL-PCB levels in meat from broilers and rabbits fed with fish-oil enriched feeds. Chemosphere 78, 175-184.

Burnham, A.K., Criado, J.M., Pérez-Maqueda, L.A., Popescu, C., Sbirrazzuoli, N., Vyazovkin, S., 2011. ICTAC Kinetics Committee recommendations for performing kinetic computations on thermal analysis data.

Caballero, J.A., Conesa, J.A., 2005. Mathematical considerations for nonisothermal kinetics in thermal decomposition. Journal of Analytical and Applied Pyrolysis 73, 85-100.

Caballero, J.A., Conesa, J.A., 2011. New approach to thermal analysis kinetics by considering several first order reactions. Thermochimica Acta 525, 40-49. 
Cai, Q.-Y., Mo, C.-H., Wu, Q.-T., Zeng, Q.-Y., Katsoyiannis, A., 2007. Occurrence of organic contaminants in sewage sludges from eleven wastewater treatment plants, China. Chemosphere 68, 1751-1762.

Cleverly, D.S., J.; Schweer, G.; Becker, J.; Winters, D., 1997. The Congener Profiles of Anthropogenic Sources of Chlorinated Dibenzo-p-Dioxins and Chlorinated Dibenzofurans in the United States. Organohalogen Compd. 32, 430-435.

Coe, J.M., Rogers, D.E., 1997. Marine Debris: Sources, Impacts and Solutions. Springer, New York.

Conesa, J.A., Fullana, A., Font, R., 2005a. Dioxin production during the thermal treatment of meat and bone meal residues. Chemosphere 59, 85-90.

Conesa, J.A., Galvez, A., 2006. Organic pollutants in air close to cement kilns. Organohalogen Compounds 68, 1022.

Conesa, J.A., Galvez, A., Font, R., Martin-Gullon, I., Moltó, J., 2005b. Preliminary study of the interaction between pollutants and cement raw material Organohalogen Compounds 67, 2253.

Conesa, J.A., Gálvez, A., Fullana, A., 2008. Decomposition of paper wastes in presence of ceramics and cement raw material. Chemosphere 72, 306-311.

Conesa, J.A., Rey, L., Egea, S., Rey, M.D., 2011. Pollutant formation and emissions from cement kiln stack using a solid recovered fuel from municipal solid waste. Environ. Sci. Technol. 45, 5878-5884.

Derraik, J.G.B., 2002. The pollution of the marine environment by plastic debris: a review. Marine Pollution Bulletin 44, 842-852.

Font, R., Moltó, J., Egea, S., Conesa, J.A., 2011. Thermogravimetric kinetic analysis and pollutant evolution during the pyrolysis and combustion of mobile phone case. Chemosphere 85, 516-524.

Fuentes, M.J., Font, R., Gómez-Rico, M.F., Martín-Gullón, I., 2007. Pyrolysis and combustion of waste lubricant oil from diesel cars: Decomposition and pollutants. Journal of Analytical and Applied Pyrolysis 79, 215-226.

Galgani, F., Fleet, D., van Franeker, J., Katsanevakis, S., Maes, T., Mouat, J., Oosterbaan, L., Poitou, I., Hanke, G., Thompson, R., 2010. Marine Strategy Framework directive-Task Group 10 Report marine litter do not cause harm to the coastal and marine environment. Report on the identification of descriptors for the Good Environmental Status of European Seas regarding marine litter under the Marine Strategy Framework Directive. Office for Official Publications of the European Communities.

Galgani, F., Fleet, D., Van Franeker, J., Katsanevakis, S., Maes, T., Mouat, J., Oosterbaan, L., Poitou, I., Hanke, G., Thompson, R., Amato, E., Birkun, A., Janssen, C., Marine Strategy Framework Directive - Task Group 10 Report Marine Litter. In: Zampoukas, N. (Ed.), JRC Scientific and Technical Reports. European Commission Joint Research Centre, Ispra, (2010)

Garrido, M.A., Font, R., Conesa, J.A., 2016. Pollutant emissions during the pyrolysis and combustion of flexible polyurethane foam. Waste Management 52, 138-146.

Garrido, M.A., Font, R., Conesa, J.A., 2017. Pollutant emissions from the pyrolysis and combustion of viscoelastic memory foam. Science of The Total Environment 577, 183-194.

Gaylor, M.O., Harvey, E., Hale, R.C., 2012. House crickets can accumulate polybrominated diphenyl ethers (PBDEs) directly from polyurethane foam common in consumer products. Chemosphere 86, 500-505.

Gregory, M.R., 2009. Environmental implications of plastic debris in marine settingsentanglement, ingestion, smothering, hangers-on, hitch-hiking and alien invasions. Philosophical Transactions of the Royal Society of London B: Biological Sciences 364, 20132025. 
Grønli, M.G., Várhegyi, G., Di Blasi, C., 2002. Thermogravimetric analysis and devolatilization kinetics of wood. Industrial and Engineering Chemistry Research 41, 4201-4208.

Hagstrom, B., Hampton, R.N., Helmesjo, B., Hjertberg, T., 2006. Disposal of cables at the "end of life"; some of the environmental considerations. Electrical Insulation Magazine, IEEE 22, 21-30.

Heo, N., Hong, S., Han, G., Hong, S., Lee, J., Song, Y., Jang, M., Shim, W., 2013. Distribution of small plastic debris in cross-section and high strandline on Heungnam beach, South Korea. Ocean Sci. J. 48, 225-233.

Hidalgo-Ruz, V., Gutow, L., Thompson, R.C., Thiel, M., 2012. Microplastics in the Marine Environment: A Review of the Methods Used for Identification and Quantification. Environmental Science \& Technology 46, 3060-3075.

Holmes, L.A., Turner, A., Thompson, R.C., 2012. Adsorption of trace metals to plastic resin pellets in the marine environment. Environmental Pollution 160, 42-48.

Iñiguez, M.E., Conesa, J.A., Fullana, A., 2016. Marine debris occurrence and treatment: A review.

Jambeck, J.R., Geyer, R., Wilcox, C., Siegler, T.R., Perryman, M., Andrady, A., Narayan, R., Law, K.L., 2015. Plastic waste inputs from land into the ocean. Science 347, 768-771.

Jung, R.-T., Sung, H.G., Chun, T.-B., Keel, S.-I., 2010. Practical engineering approaches and infrastructure to address the problem of marine debris in Korea. Marine Pollution Bulletin 60, 1523-1532.

Martín-Gullón, I., Gómez-Rico, M.F., Fullana, A., Font, R., 2003. Interrelation between the kinetic constant and the reaction order in pyrolysis. Journal of Analytical and Applied Pyrolysis 68-69, 645-655.

Martins, J., Sobral, P., 2011. Plastic marine debris on the Portuguese coastline: A matter of size? Marine Pollution Bulletin 62, 2649-2653.

Mato, Y., Isobe, T., Takada, H., Kanehiro, H., Ohtake, C., Kaminuma, T., 2001. Plastic Resin Pellets as a Transport Medium for Toxic Chemicals in the Marine Environment. Environmental Science \& Technology 35, 318-324.

Moliner, C., Bosio, B., Arato, E., Ribes, A., 2016. Thermal and thermo-oxidative characterisation of rice straw for its use in energy valorisation processes. Fuel 180, 71-79.

Moltó, J., Conesa, J.A., Font, R., Martín-Gullón, I., 2005. Organic compounds produced during the thermal decomposition of cotton fabrics. Environ. Sci. Technol. 39, 5141-5147.

Moltó, J., Font, R., Conesa, J.A., 2006. Study of the organic compounds produced in the pyrolysis and combustion of used polyester fabrics. Energy Fuels 20, 1951-1958.

Moreno, A.I., Font, R., Conesa, J.A., 2016. Characterization of gaseous emissions and ashes from the combustion of furniture waste. Waste Manage. (Oxford) Intended for publication.

Mouat, J., Lopez Lozano, R., Bateson, H., 2010. Economic impacts of marine litter. Kommunenes Internasjonale Miljøorganisasjon (KIMO International), UK.

Niu, S., Chen, M., Li, Y., Xue, F., 2016. Evaluation on the oxy-fuel combustion behavior of dried sewage sludge. Fuel 178, 129-138.

Orrego, R., Jiménez, B., Bordajandi, L.R., Gavilán, J.F., Inzunza, B., Abad, E., González, M.J., Rivera, J., Barra, R., 2005. EROD induction and PCDD/F levels in fish liver from the Biobio River in Chile. Chemosphere 60, 829-835.

OSPAR, 2007. OSPAR Pilot Project on Monitoring Marine Beach Litter: Monitoring of marine litter on beaches in the OSPAR region. OSPAR Commission, London.

Rochman, C.M., Hoh, E., Hentschel, B.T., Kaye, S., 2013a. Long-Term Field Measurement of Sorption of Organic Contaminants to Five Types of Plastic Pellets: Implications for Plastic Marine Debris. Environmental Science \& Technology 47, 1646-1654.

Rochman, C.M., Manzano, C., Hentschel, B.T., Simonich, S.L.M., Hoh, E., 2013b. Polystyrene Plastic: A Source and Sink for Polycyclic Aromatic Hydrocarbons in the Marine Environment. Environmental Science \& Technology 47, 13976-13984. 
Rovira, J., Vilavert, L., Nadal, M., Schuhmacher, M., Domingo, J.L., 2015. Temporal trends in the levels of metals, PCDD/Fs and PCBs in the vicinity of a municipal solid waste incinerator. Preliminary assessment of human health risks. Waste Manage. (Oxford) 43, 168-175.

Song, Y., Wang, F., Bian, Y., Zhang, Y., Jiang, X., 2012. Chlorobenzenes and organochlorinated pesticides in vegetable soils from an industrial site, China. Journal of Environmental Sciences 24, 362-368.

Teuten, E.L., Saquing, J.M., Knappe, D.R.U., Barlaz, M.A., Jonsson, S., Björn, A., Rowland, S.J., Thompson, R.C., Galloway, T.S., Yamashita, R., Ochi, D., Watanuki, Y., Moore, C., Viet, P.H., Tana, T.S., Prudente, M., Boonyatumanond, R., Zakaria, M.P., Akkhavong, K., Ogata, Y., Hirai, H., Iwasa, S., Mizukawa, K., Hagino, Y., Imamura, A., Saha, M., Takada, H., 2009. Transport and release of chemicals from plastics to the environment and to wildlife. Philosophical Transactions of the Royal Society of London B: Biological Sciences 364, 2027-2045.

Thompson, R.C., Moore, C.J., vom Saal, F.S., Swan, S.H., 2009. Plastics, the environment and human health: current consensus and future trends. Philosophical Transactions of the Royal Society of London B: Biological Sciences 364, 2153-2166.

Tri, T.M., Anh, H.Q., Tham, T.T., Van Quy, T., Long, N.Q., Nhung, D.T., Nakamura, M., Nishida, M., Maeda, Y., Van Boi, L., Minh, T.B., Distribution and depth profiles of polychlorinated dibenzo-p-dioxins, polychlorinated dibenzofurans, and polychlorinated biphenyls in sediment collected from offshore waters of Central Vietnam. Marine Pollution Bulletin.

UNE-EN ISO 2016. Solid biofuels - Determination of ash conten, 18122:2016. AENOR, Spain.

UNEP-CAR/RCU, 2008. Marine Litter in the Wider Caribbean Region: A Regional Overview. United Nations Environment Programme, Nairobi, p. 81.

UNEP, 2005. Marine Litter an Analytical Overview. United Nations Environment Programme, Kenya, p. 47.

UNEP, 2009. Marine Litter: A Global Challenge. Nairobi: UNEP, 232

US EPA, 1994b. Method 1613. Tetra- through Octa-Chlorinated Dioxins and Furans by Isotope Dilution HRGC/HRMS. United States Environmental Protection Agency. Office of Solid Waste, Springfield: National Technical Information Service.

US EPA, 1998. Handbook for air toxic emission inventory development. Volume I: Stationary sources. United States Environmental Protection Agency. Office of Air Quality Planning and Standards.

US EPA, 2007a. Method 3545A: Pressurized Fluid Extraction (PFE). Revision 1. United States Environmental Protection Agency. Office of Solid Waste, Washington, D.C., pp. 1-16.

US EPA, 2007b. Method 8270D. Semivolatile organic compounds by GC/MS, in: US EPA (Ed.), SW-846. United States Environmental Protection Agency, Office of Water, Office of Science and Technology, Washington, D.C.

US EPA, 2007c. Method 8270D. Semivolatile organic compounds by GC/MS. United States Environmental Protection Agency. Office of Solid Waste, Washington, D.C.

US EPA, 2010. Method 1668C. Chlorinated Biphenyl Congeners in Water, Soil, Sediment, Biosolids, and Tissue by HRGC/HRM. United States Environmental Protection Agency. Office of Water. Office of Science and Technology, Washington, D.C.

Várhegyi, G., 2007. Aims and methods in non-isothermal reaction kinetics. Journal of Analytical and Applied Pyrolysis 79, 278-288.

Vyazovkin, S., 2000. On the phenomenon of variable activation energy for condensed phase reactions. New Journal of Chemistry 24, 913-917.

Vyazovkin, S., Burnham, A.K., Criado, J.M., Pérez-Maqueda, L.A., Popescu, C., Sbirrazzuoli, N., 2011a. ICTAC Kinetics Committee recommendations for performing kinetic computations on thermal analysis data. Thermochimica Acta 520, 1-19.

Vyazovkin, S., Burnham, A.K., Criado, J.M., Pérez-Maqueda, L.A., Popescu, C., Sbirrazzuoli, N., 2011b. ICTAC Kinetics Committee recommendations for performing kinetic computations on thermal analysis data. Thermochimica Acta 520, 1-19. 


\section{TABLE LEGENDS}

Table 1. Analysis of marine debris used (wt. \% in all cases).

Table 2. Dioxin and furans (PCDD/Fs) content (two samples).

Table 3. Polychlorinated biphenyls (PCBs) analysis performed in the MDs samples.

Table 4. Kinetic constants for the thermal decomposition of different plastics in N2:O2=4:1 atmosphere.

\section{FIGURE CAPTIONS}

Figure 1. Scatter plots of the two first principal components. The points represents different sample origins (marked in the text).

Figure 2. Thermal decomposition of main plastics found in marine ambient at $20 \mathrm{~K} / \mathrm{min}$ in $\mathrm{N} 2: \mathrm{O} 2=4: 1$ atmosphere. Experimental and calculated curves.

Figure 3. Thermal decomposition of MDs at 5,10 and $20 \mathrm{~K} / \mathrm{min}$ in N2:O2=4:1 atmosphere. Experimental and simulated curves.

Figure 4. Thermal decomposition of MDs at 5,10 and $20 \mathrm{~K} / \mathrm{min}$ in Nitrogen and in N2:O2=9:1 atmosphere.

Table 1. Analysis of marine debris used (wt. \% in all cases).

\begin{tabular}{lc}
\hline & Inmediate analysis \\
Humidity & 9,3 \\
Ashes & 29,1 \\
\hline \multicolumn{2}{c}{ Elemental analysis } \\
$\mathrm{C}$ & 38,2 \\
$\mathrm{H}$ & 4,89 \\
$\mathrm{~N}$ & 0,28 \\
$\mathrm{~S}$ & 0.098 \\
$\mathrm{O}$ (by difference) & 27,52 \\
\multicolumn{2}{c}{ Ionic chromatography } \\
\hline Fluorine & 0,00524 \\
Chlorine & 1,83 \\
Bromine & 0,00786 \\
\hline
\end{tabular}

n.d. $=$ not detected 
Table 2. Dioxin and furans (PCDD/Fs) content (two samples).

\begin{tabular}{|l|c|c|}
\hline \multicolumn{1}{|c|}{ Congener } & $\begin{array}{c}\text { Sample } \\
\text { MDs 1 } \\
\text { pg/g }\end{array}$ & $\begin{array}{c}\text { Sample } \\
\text { MDs 1 } \\
\text { pg/g }\end{array}$ \\
\hline $2,3,7,8-\mathrm{TCDF}$ & 0,8 & 0,7 \\
$1,2,3,7,8-\mathrm{PeCDF}$ & 0,1 & 0,2 \\
$2,3,4,7,8-\mathrm{PeCDF}$ & 0,4 & 0,4 \\
$1,2,3,4,7,8-\mathrm{HxCDF}$ & 0,4 & 1,3 \\
$1,2,3,6,7,8-\mathrm{HxCDF}$ & 0,2 & 1,0 \\
$2,3,4,6,7,8-\mathrm{HxCDF}$ & 3,2 & 3,2 \\
$1,2,3,7,8,9-\mathrm{HxCDF}$ & 0,3 & 0,4 \\
$1,2,3,4,6,7,8-\mathrm{HpCDF}$ & 1,3 & 1,4 \\
$1,2,3,4,7,8,9-\mathrm{HpCDF}$ & 0,6 & 1,1 \\
OCDF & 1,2 & 0,9 \\
\hline $2,3,7,8-\mathrm{TCDD}$ & 0,0 & 0,0 \\
$1,2,3,7,8-\mathrm{PeCDD}$ & 0,3 & 0,2 \\
$1,2,3,4,7,8-\mathrm{HxCDD}$ & 0,0 & 0,0 \\
$1,2,3,6,7,8-\mathrm{HxCDD}$ & 0,3 & 0,6 \\
$1,2,3,7,8,9-\mathrm{HxCDD}$ & 0,1 & 0,3 \\
$1,2,3,4,6,7,8-\mathrm{HpCDD}$ & 3,0 & 2,7 \\
OCDD & 4,6 & 5,8 \\
\hline Total- toxic PCDD/Fs & & \\
(pg WHO-TEQ/g) & 0,99 & 1,20 \\
\hline
\end{tabular}

Table 3. Polychlorinated biphenyls (PCBs) analysis performed in the MDs samples.

\begin{tabular}{|l|c|c|}
\hline Congener & $\begin{array}{c}\text { Sample } \\
\text { MDs 1 } \\
\text { pg/g }\end{array}$ & $\begin{array}{c}\text { Sample } \\
\text { MDs 2 } \\
\mathbf{p g} / \mathbf{g}\end{array}$ \\
\hline PCB-81 & 1,5 & 1,4 \\
PCB-77 & 17,3 & 16,6 \\
PCB-123 & 11,2 & 11,0 \\
PCB-118 & 106,3 & 105,1 \\
PCB-114 & 1,3 & 2,2 \\
PCB-105 & 39,8 & 38,9 \\
PCB-126 & 4,2 & 4,1 \\
PCB-167 & 33,7 & 30,7 \\
PCB-156 & 35,6 & 34,4 \\
PCB-157 & 10,7 & 5,2 \\
PCB-169 & 1,8 & 1,4 \\
PCB-189 & 14,2 & 14,2 \\
\hline Total-PCBs (pgWHO-TEQ/g) & 0,486 & 0,457 \\
\hline
\end{tabular}


Table 4. Kinetic constants for the thermal decomposition of different plastics in $\mathrm{N}_{2}: \mathrm{O}_{2}=4: 1$ atmosphere.

\begin{tabular}{|c|c|c|}
\hline \multirow[t]{5}{*}{ Nylon } & $\mathrm{k}_{01}, \mathrm{~s}^{-1}$ & $1,83 E+05$ \\
\hline & $\mathrm{E}_{1}, \mathrm{~kJ} \mathrm{~mol}^{-1}$ & 112,46 \\
\hline & $\mathrm{c}_{\mathrm{s} 10}$ & 0.17 \\
\hline & $\mathrm{k}_{02}, \mathrm{~s}^{-1}$ & $2,85 \mathrm{E}+09$ \\
\hline & $\mathrm{E}_{2}, \mathrm{~kJ} \mathrm{~mol}^{-1}$ & 158.76 \\
\hline \multirow[t]{5}{*}{ PE } & $\mathrm{k}_{01}, \mathrm{~s}^{-1}$ & $4,95 E+07$ \\
\hline & $\mathrm{E}_{1}, \mathrm{~kJ} \mathrm{~mol}^{-1}$ & 127,28 \\
\hline & $\mathrm{c}_{\mathrm{s} 10}$ & 0,86 \\
\hline & $\mathrm{k}_{02}, \mathrm{~s}^{-1}$ & $2,05 E+14$ \\
\hline & $\mathrm{E}_{2}, \mathrm{~kJ} \mathrm{~mol}^{-1}$ & 232,36 \\
\hline \multirow[t]{2}{*}{ PP } & $\mathrm{k}_{01}, \mathrm{~s}^{-1}$ & $6.28 \mathrm{E}+05$ \\
\hline & $\mathrm{E}_{1}, \mathrm{~kJ} \mathrm{~mol}^{-1}$ & 93.51 \\
\hline \multirow[t]{5}{*}{ PET } & $\mathrm{k}_{01}, \mathrm{~s}^{-1}$ & $1,23 E+07$ \\
\hline & $\mathrm{E}_{1}, \mathrm{~kJ} \mathrm{~mol}^{-1}$ & 140,22 \\
\hline & $\mathrm{C}_{\mathrm{s} 10}$ & 0,27 \\
\hline & $\mathrm{k}_{02}, \mathrm{~s}^{-1}$ & $5,95 E+16$ \\
\hline & $\mathrm{E}_{2}, \mathrm{~kJ} \mathrm{~mol}^{-1}$ & 254,21 \\
\hline \multirow[t]{2}{*}{ PS } & $\mathrm{k}_{01}, \mathrm{~s}^{-1}$ & $1,61 E+11$ \\
\hline & $\mathrm{E}_{1}, \mathrm{~kJ} \mathrm{~mol}^{-1}$ & 166,44 \\
\hline
\end{tabular}




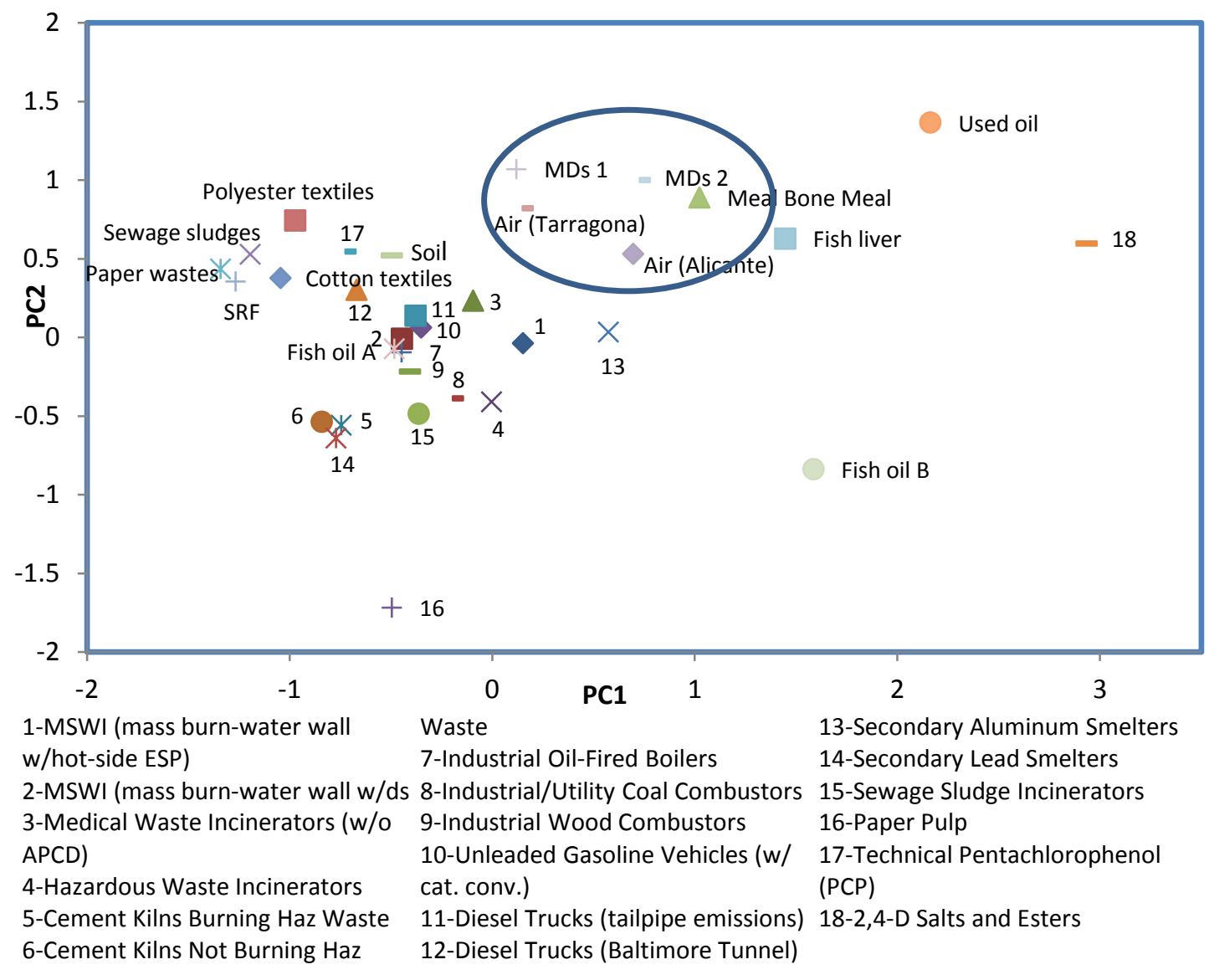

Figure 1. Scatter plots of the two first principal components. The points represent different sample origins (marked in the text).

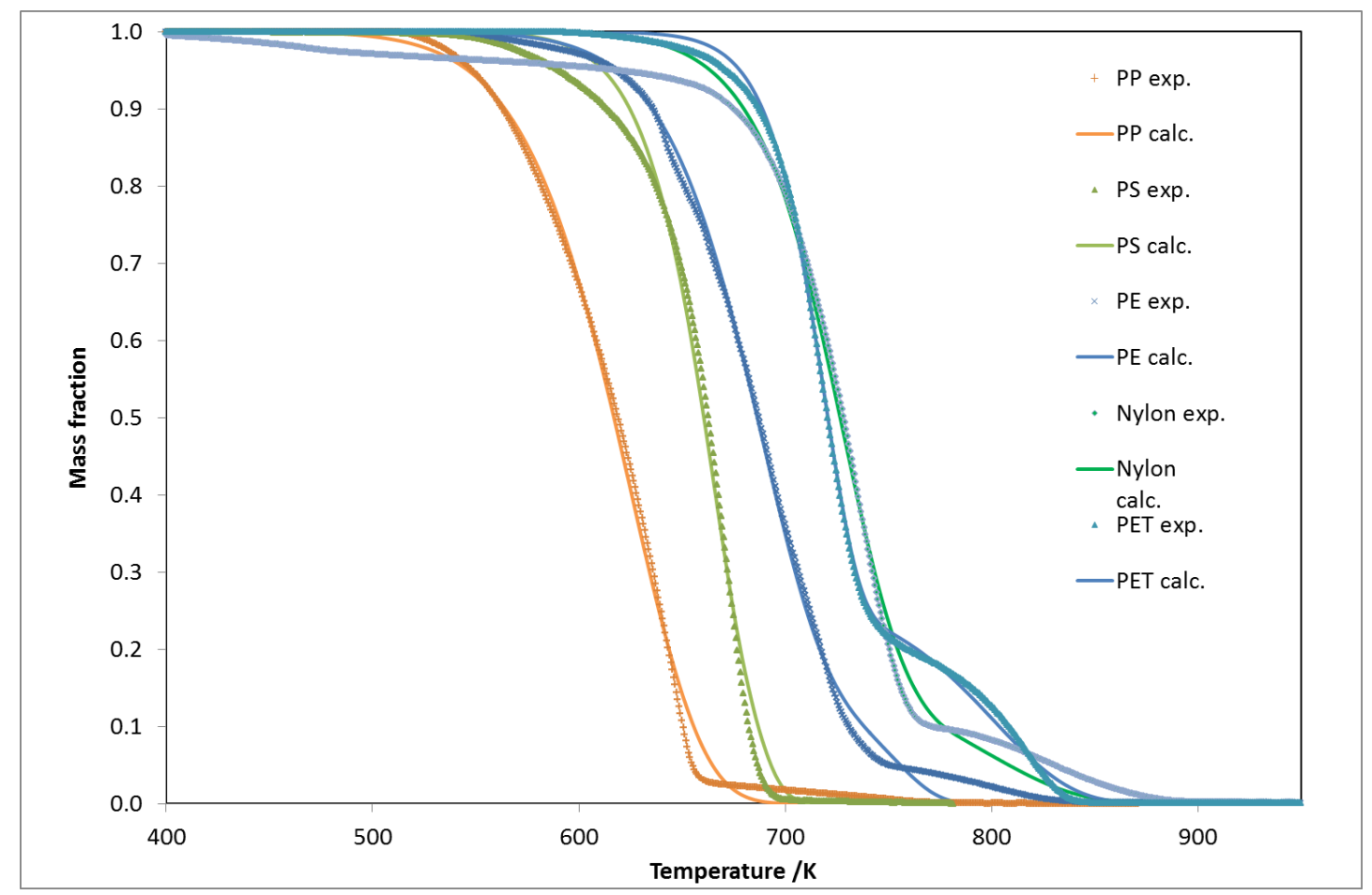

Figure 2. Thermal decomposition of main plastics found in marine ambient at $20 \mathrm{~K} / \mathrm{min}$ in $\mathrm{N}_{2}: \mathrm{O}_{2}=4: 1$ atmosphere. Experimental and calculated curves. 


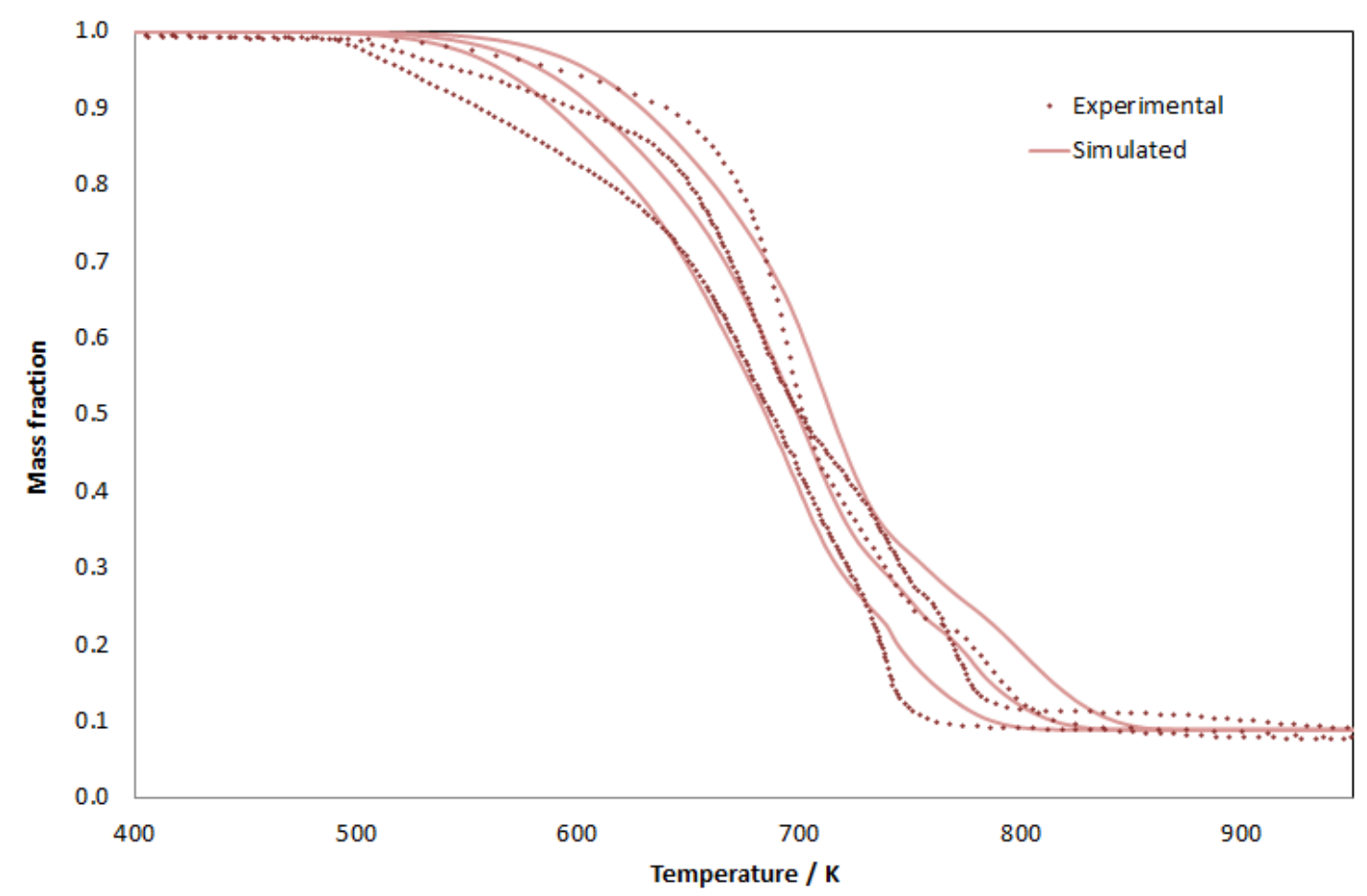

Figure 3. Thermal decomposition of MDs at 5,10 and $20 \mathrm{~K} / \mathrm{min}$ in $\mathrm{N}_{2}: \mathrm{O}_{2}=4: 1$ atmosphere. Experimental and simulated curves.

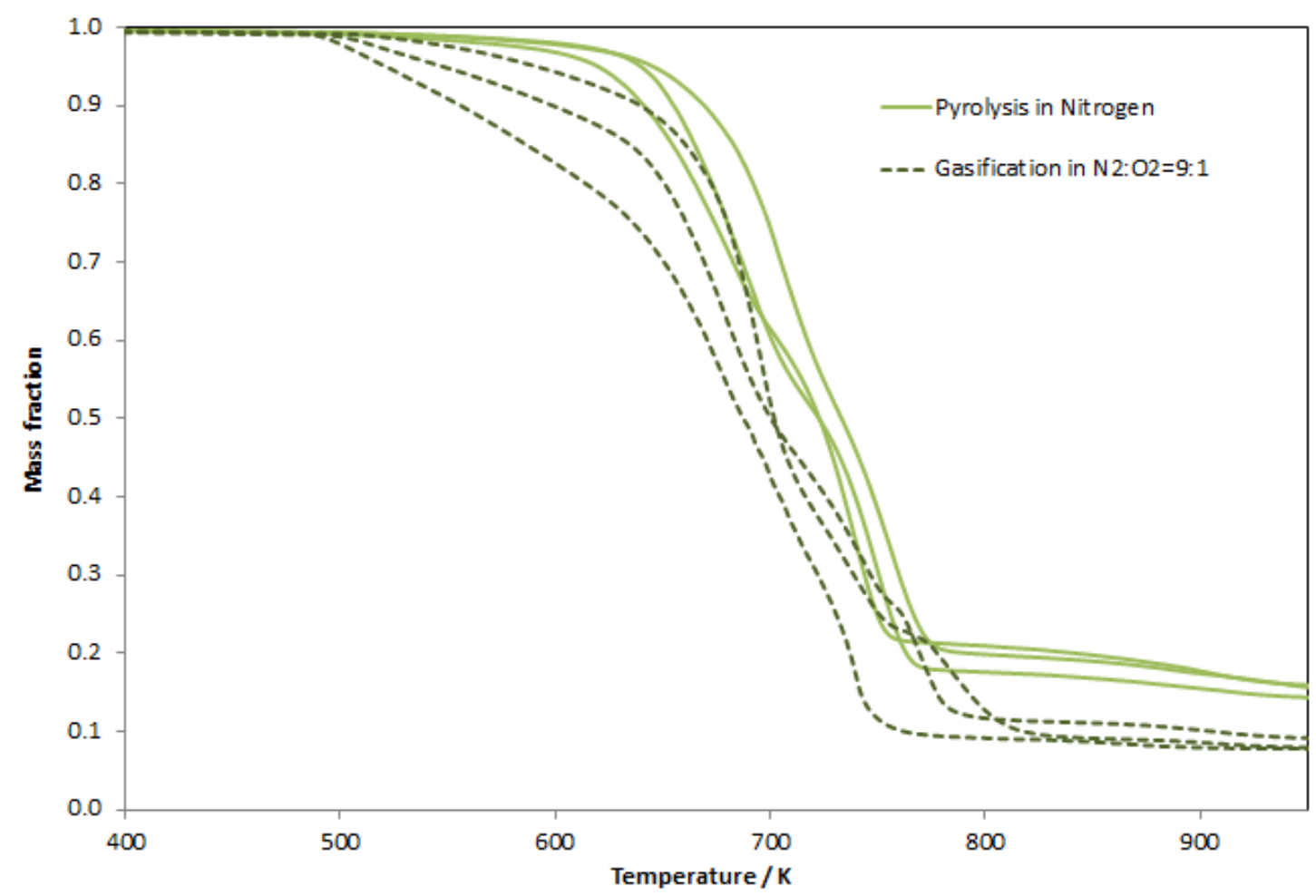

Figure 4. Thermal decomposition of MDs at 5,10 and $20 \mathrm{~K} / \mathrm{min}$ in Nitrogen and in $\mathrm{N}_{2}: \mathrm{O}_{2}=9: 1$ atmosphere. 